\title{
Exotic option, stochastic volatility and incentive scheme
}

\author{
J. Tang \& S. S.-T. Yau \\ Department of Mathematics, Statistics and Computer Science, \\ University of Illinois at Chicago, USA
}

\begin{abstract}
This paper examines the impact of incentive fee on exotic option pricing when the volatility is a stochastic process and is correlated with the underlying asset price. Since high water mark (HWM) is the benchmark employed by incentive schemes in the hedge fund industry, we first develop the HWM lookback optionpricing framework in stochastic volatility model. This provides an improvement to previous works in constant volatility model. We also explore option prices through Monte Carlo (MC) simulation and variance reduction technique. We further demonstrate that our discrete simulation to HWM option pricing is more practical than models assuming continuous collection of incentive fees. Numerical examples illustrate how the stochastic volatility models and incentive scheme influence option pricing.

Keywords: lookback option, stochastic volatility models, high water mark, risk neutral, Monte Carlo simulation, variance reduction.
\end{abstract}

\section{Introduction}

Over the last few years, hedge funds have been experiencing significant growth in both the number of hedge funds and the amount of assets under management. Based on the estimates by Securities and Exchange Commission, there are currently around 8,000 hedge funds in the United States managing around \$1 trillion in assets. Hedge fund assets are growing faster than mutual fund assets and have roughly one quarter of the assets of mutual funds. They often provide markets and investors with substantial benefits, such as enhancing liquidity, contributing to market efficiency by taking speculative and value-driven trading 
position, and offering investors an important risk management tool by providing valuable portfolio diversification.

Compensation schemes, which align manager interests with investor interests, play an important role in financial market. Hedge fund industries usually employ a never negative incentive fee (NNIF) [4] structure, and use a high water mark (HWM) as the benchmark, which increases over time to make up for previous failures to exceed the target. Fung and Hsieh [6] provide a rationale for the organization of hedge funds and demonstrate the incentive fee paid to successful managers can be significantly higher than the fixed management fee. Carpenter [3] and Basak, Pavlova, and Shapiro [1] examine effects of the incentive compensation on the optimal dynamic investment strategies. Goetzmann, Ingersoll and Ross [7] utilize an option approach to calculate the present value of the fees charged by money managers.

One of the factors that provide an explanation for the recent success of exotic options is their significant hedging role, which meets the hedgers' needs in cost effective ways. The exotic option price derived from the Black-Scholes model [2] under constant volatility assumption could be wildly wrong since most derivative markets exhibit persistently varying volatilities. Li's [11] study of the HWM lookback option in the constant volatility model, under the assumption of incentive fee collected continuously, is not very practical since the fee is usually collected monthly or quarterly in practice. In this paper, we first use MC method to study the price of path dependent HWM lookback option in a stochastic volatility model, in which the stock price and volatility are instantaneously correlated. Then, the framework of the HWM option pricing is set up with stochastic volatility and HWM lookback option is simulated by Monte Carlo discretion and variance reduction technique. Finally, some numerical examples and results are given.

\section{HWM option pricing framework}

Consider a time interval $[0, T]$ and fix a two-dimensional standard Brownian Motion process $W=\left(W^{(1)}, W^{(2)}\right)$ on a complete filtered probability space $(\Omega$, $\mathcal{F}, \mathrm{P})$. Let the filtration $\mathrm{F}=\left\{\mathcal{F}_{\mathrm{t}}: 0 \leq \mathrm{t} \leq \mathrm{T}\right\}$ be the $P$-augmentation [16] of the natural filtration of $W$. Hence the uncertainty in this setup is generated by the process $W$ and the flow of information is represented by the filtration $\mathrm{F}$. We say $W_{t}^{(1)}$ and $W_{t}^{(2)}$ are correlated Standard Brownian Motions with correlation $\rho$ if $E\left(W_{t}^{(1)} W_{t}^{(2)}\right)=\rho . t$.

Now assume an arbitrage-free financial market consisting of two traded assets in which trading takes place continuously over the period $[0, T]$ : one locally risk-free asset $B$ with risk-free interest rate $r$, and one risky asset of price $\mathrm{S}$ (called the primitive asset). We define the time $t$ prices of the asset of the fund as the solution to the following stochastic differential equation

$$
d S_{t}=(r-D) S_{t} d t+\sigma_{t} S_{t} \cdot d Z_{t}, \quad S_{t}<H_{t}
$$


where $D$ is the basic management fee, $\sigma$ is the volatility process, to be discussed in a moment. $Z$ for $0 \leq t \leq T$ is a standard Brownian Motion (SBM). The correlation between volatility process and the return process of the primitive asset is represented by a constant $\rho \in[0,1] . H_{t}$ is the HWM at time $t$.

We consider two different dynamics for the volatility process $\sigma$. The first is the Geometric Brownian Motion Process (GBMP) [10, 13],

$$
d \sigma_{t}=\alpha \sigma_{t} d t+\theta \sigma_{t} d W_{t}^{(\sigma)}, \quad 0 \leq t \leq T
$$

where the appreciation rate $\alpha$ and the volatility of the volatility $\theta$ are constants. Obviously, $\sigma_{t} / \sigma_{0}$ is lognormal with parameters $\left(\alpha-\theta^{2} / 2\right) T$ and $\theta \sqrt{T}$. The second is the Square Root Mean Reverting Process (SRMRP) [9].

$$
d v_{t}=k\left(\bar{v}-v_{t}\right) d t+\theta \sqrt{v_{t}} d W_{t}^{(\sigma)}, \quad 0 \leq t \leq T
$$

where $v$ is square of $\sigma, \bar{v}$ is the long-run mean variance, and $k$ represents the speed of mean reversion. Feller [5] has shown that the density of $v_{t}$ at time $t>0$ conditioned on $v_{0}$ at $t=0$ follows a non-central chi-square distribution with $4 k \bar{v} / \theta^{2}$ degrees of freedom.

Since $Z_{t}$ and $W_{t}^{(\sigma)}$ are correlated SBMs with correlation $\rho$, for the sake of better simulation of $Z_{t}$ in later section, we can write $Z_{t}=\sqrt{1-\rho^{2}} W_{t}^{(s)}+\rho \cdot W_{t}^{(\sigma)}$ just by the property of SBM, where $W_{t}^{(s)}$ is a SBM independent of $W_{t}^{(\sigma)}$, for detail, see [15]. Then eqn (1) can now be written as follows:

$$
d S_{t}=(r-D) S_{t} d t+\sigma_{t} S_{t} \cdot\left(\sqrt{1-\rho^{2}} d W_{t}^{(s)}+\rho d W_{t}^{(\sigma)}\right), \quad S_{t}<H_{t}
$$

In the simplest case, the HWM is the highest level the asset value that has reached in the past. For some incentive contracts, the HWM grows at the rate of interest or other contractually stated rate $G_{t}$, thus evolution of $H_{t}$ is locally deterministic as Goetzmann, Ingersoll and Ross [7] point out.

$$
d H_{t}=G_{t} H_{t} d t, \quad S_{t}<H_{t}
$$

where $G_{t}$, the contractual growth rate of the HWM, is usually zero or $r$. When the primitive asset value reaches a new high, the HWM is reset to this higher level.

Following the arguments in Hull and White [10], there are three state variables, $S, \sigma$ and $H$, of which $S$ is traded. When the fund's assets are below the HWM and the volatility is a GBMP, the option price $V_{t}$ satisfies the following partial differential equation (PDE)

$$
\begin{aligned}
\frac{\partial V}{\partial t}+\frac{1}{2} S^{2} \sigma^{2} & \frac{\partial^{2} V}{\partial S^{2}}+\frac{1}{2} \theta^{2} \sigma^{2} \frac{\partial^{2} V}{\partial \sigma^{2}}+\rho \theta S \sigma^{2} \frac{\partial^{2} V}{\partial S \partial \sigma} \\
& +G H \frac{\partial V}{\partial H}+S(r-D) \frac{\partial V}{\partial S}+\alpha \sigma \frac{\partial V}{\partial \sigma}=r V, \quad S<H
\end{aligned}
$$


if the volatility is a SRMRP, the PDE can be written as

$$
\begin{aligned}
\frac{\partial V}{\partial t}+\frac{1}{2} S^{2} v \frac{\partial^{2} V}{\partial S^{2}}+\frac{1}{2} \theta^{2} v \frac{\partial^{2} V}{\partial v^{2}}+\rho \theta S v \frac{\partial^{2} V}{\partial S \partial v} & \\
+G H \frac{\partial V}{\partial H}+S(r-D) \frac{\partial V}{\partial S}+k(\bar{v}-v) \frac{\partial V}{\partial v}=r V, & \mathrm{~S}<H
\end{aligned}
$$

The payoff function is

$$
V(S, v, H, T)=\Lambda(S, H, T),
$$

where $\Lambda(S, H, T)$ is defined in the contract. Another condition applies along the boundary $S_{t}=H_{t}$. When the asset value rises above $H_{t}$ to $H_{t}+\varepsilon_{H}$, the HWM is reset to $H_{t}+\varepsilon_{H}$, and an incentive fee of $q \cdot \varepsilon$, where $q=$ the rate of incentive fee, is paid to the manager reducing the asset value to $H_{t}+\varepsilon_{H}(1-q)$. Therefore, the option price before any adjustments of the incentive fee and HWM is $V\left(H_{t}+\varepsilon_{H}, v_{t}+\Delta v, H_{t}, t+\Delta t\right)$, and the option price after the adjustments of the incentive fee and HWM is $V\left(H_{t}+\varepsilon_{H}(1-q), v_{t}+\Delta v, H_{t}+\varepsilon_{H}, t+\Delta t\right)$. As we know that the option price is continuous. It gives

$$
V\left(H_{t}+\varepsilon_{H}, v_{t}+\Delta v, H_{t}, t+\Delta t\right)=V\left(H_{t}+\varepsilon_{H}(1-q), v_{t}+\Delta v, H_{t}+\varepsilon_{H}, t+\Delta t\right)
$$

or omitting higher orders of $\varepsilon_{H}, \Delta v$ and $\Delta t$, we have

$$
\begin{gathered}
V_{t}+\frac{\partial V_{t}}{\partial S_{t}} \varepsilon_{H}+\frac{\partial V_{t}}{\partial v_{t}} \Delta v+\frac{\partial V_{t}}{\partial t} \Delta t= \\
V_{t}+\frac{\partial V_{t}}{\partial S_{t}}(1-q) \varepsilon_{H}+\frac{\partial V_{t}}{\partial v_{t}} \Delta v+\frac{\partial V_{t}}{\partial H_{t}} \varepsilon_{H}+\frac{\partial V_{t}}{\partial t} \Delta t .
\end{gathered}
$$

giving the boundary condition

$$
q \frac{\partial V_{t}}{\partial S_{t}}=\frac{\partial V_{t}}{\partial H_{t}} \quad \text { on } \quad S_{t}=H_{t} .
$$

Hence eqn (6) or eqn (7) together with eqn (8) and eqn (9) give the solution of the option price with the HWM provision in different stochastic volatility models.

From a probability view, the current value of a floating strike lookback put option with payoff $\left(M_{T}-S_{T}\right)$ is the discounted expectation of the payoff under the risk neutral measure.

$$
V(S, M, \sigma, 0)=e^{-r T} E\left[M_{T}-S_{T}\right],
$$

where $M_{t}=\max _{0 \leq u \leq t}\left\{S_{u}\right\}$. Define $I_{n}=\int_{0}^{t}\left(S_{\tau}\right)^{n} d \tau$ and $M_{n}=\left(I_{n}\right)^{1 / n}$, we consider a lookback option whose value depends on $M_{n}$ and then take the limit as $n \rightarrow \infty$. Recall that as $n$ tends to infinity and by stochastic calculus, we have $M_{t}=\lim _{n \rightarrow \infty} M_{n}=\max _{0 \leq \tau \leq t} S_{\tau}$ [14]. Then we derive the stochastic differential 
equation satisfied by $M_{n}$, we get $d M_{n}=\frac{1}{n} \frac{S^{n}}{(M)^{n-1}} d t$, thus $M_{n}$ is a deterministic variable [14], as there are no random terms on the right hand side. Since the HWM lookback put is a path-dependent option, its value $V$ is not simply a function of $S, \sigma, H$ and $t$, but also on $M$. If the volatility is a SRMRP, we actually have

$$
\begin{aligned}
\frac{\partial V}{\partial t}+\frac{1}{2} S^{2} v \frac{\partial^{2} V}{\partial S^{2}}+\frac{1}{2} \theta^{2} v \frac{\partial^{2} V}{\partial v^{2}}+\rho \theta S v \frac{\partial^{2} V}{\partial S \partial v}+G H \frac{\partial V}{\partial H} & \\
& \frac{1}{n} \frac{S^{n}}{\left(M_{n}\right)^{n-1}} \frac{\partial V}{\partial M}+S(r-D) \frac{\partial V}{\partial S}+k(\bar{v}-v) \frac{\partial V}{\partial v}=r V, \quad 0 \leq \mathrm{S}<\mathrm{H}
\end{aligned}
$$

We now take the limit $n \rightarrow \infty$. Since $S \leq \max S=M$, in this limit the coefficient of $\frac{\partial V}{\partial M}$ tents to zero. Thus in this limit, for a HWM lookback put with payoff $\left(H_{T}-S_{T}\right)$, the option price satisfies the PDEs

$$
\begin{gathered}
\frac{\partial V}{\partial t}+\frac{1}{2} S^{2} v \frac{\partial^{2} V}{\partial S^{2}}+\frac{1}{2} \theta^{2} v \frac{\partial^{2} V}{\partial v^{2}}+\rho \theta S v \frac{\partial^{2} V}{\partial S \partial v}+G H \frac{\partial V}{\partial H} \\
+S(r-D) \frac{\partial V}{\partial S}+k(\bar{v}-v) \frac{\partial V}{\partial v}=r V, \quad 0 \leq \mathrm{S}<\mathrm{H} \\
V(S, H, \sigma, T)=H_{T}-S_{T}, \\
V(S, H, \sigma, t)=e^{-r(T-t)} E\left(H_{T}-S_{T}\right), \\
q \frac{\partial V}{\partial S}=\frac{\partial V}{\partial H}, \quad \text { on } \quad S=H .
\end{gathered}
$$

\section{HWM lookback option price simulation algorithm}

Suppose an option has payoff $\Lambda_{T} \equiv \Lambda_{T}(\omega)$ at time $T$, where $\Lambda_{T}$ may depend on the state $\omega \in \Omega$. Assuming that no arbitrage exists, under the martingale measure $P$ associated with the accumulator numernaire, the option value $V_{t}$ at time $t<T$ is

$$
V_{t}=E\left[\Lambda_{T} e^{-r(T-t)}\right],
$$

which can be solved using plain MC method. A standard reference for applications of MC methods in finance is Jäckel [11]. Eqn (16) is an integral over the state space $\Omega$,

$$
V_{t}=E\left[\Lambda_{T} e^{-r(T-t)}\right]=e^{-r(T-t)} \int_{\Omega} \Lambda_{T}(\omega) d P(\omega),
$$

which can be approximated by constructing a set $\left\{\hat{\omega}^{n}\right\}_{n=1, . ., N}$ of discrete sample paths randomly selected under a measure $\hat{P}$, a discrete approximation to the measure $P$. Then the approximation $\hat{V}_{t}$ to $V_{t}$ is 
188 Computational Finance and its Applications II

$$
\hat{V}_{t}=e^{-r(T-t)} \frac{1}{N} \sum_{n=1}^{N} \Lambda_{T}\left(\hat{\omega}^{n}\right)
$$

In our implementation, the processes $\sigma_{t}$ or $v_{t}$ and $S_{t}$ can be discretized by Euler scheme. For the simplest case, let growth rate $G$ of the HWM and the basic management fee be zero, we have MC simulation algorithm of HMW lookback put option price for the SRMRP as

for $i=1: N \quad / *$ sample path

for $j=1: M \quad / *$ time step

Initialize $H W M_{0} ; \quad / * \mathrm{HWM}_{\mathrm{P}}$ is the temporary HWM of the Pth fee paying

/* cycle for each sample path.

Initialize $H_{i, 1}=H W M_{0} ; \quad / *$ initial value of HWM

if $j<$ the pay day and $S_{i, j} \leq H_{i, j}$

Set $S_{i, j+1}=S_{i, j} \exp \left(\left(r-\frac{1}{2} \sigma_{i, j}^{2}\right) \Delta t+\sigma_{i, j}\left(\sqrt{1-\rho^{2}} \Delta W_{i, j}^{(s)}+\rho \Delta W_{i, j}^{(\sigma)}\right)\right)$;

Set $v_{i, j+1}=v_{i, j}+k\left(\bar{v}-v_{i, j}\right) \cdot \Delta t+\theta \sqrt{v_{i, j}} \cdot \Delta W_{i, j}^{(\sigma)} ;$

if $j<$ the pay day and $S_{i, j}>H_{i, j}$

Set $H_{i, j}=S_{i, j}$;

if $j=$ the day to pay incentive fee $q$ and $H_{i, j}>H W M_{P}$ of last paying cycle

Set $S_{i, j+1}=S_{i, j}-q\left(H_{i, j}-H W M_{P}\right.$ of last paying cycle);

Set $P=P+1$;

end if

Set $\hat{V}_{i}=e^{-r(T-t)}\left(H_{i, M}-S_{i, M}\right)$;

end for $j$

end for $i$

Average the discounted values over the sample paths $\hat{V}=\frac{1}{N} \sum_{i=1}^{N} \hat{V}_{i}$;

Compute the standard deviation $\sigma_{\hat{V}}=\sqrt{\frac{1}{(N-1)} \sum_{i=1}^{N}\left(\hat{V}_{i}-\hat{V}\right)^{2}}$;

Compute the standard error $\varepsilon=\sigma_{\hat{V}} / \sqrt{N}$;

\section{Examples and numerical results}

Now we present some numerical examples to demonstrate the effects of incentive scheme and different stochastic volatility models by the plain MC 
simulation. We then utilize antithetic variate (AV) variance reduction technique only for $S$, not for $\sigma$ or $v$, since the estimator is not monotone as a function of the uniforms used to generate them. The experiments are performed on a desktop PC with a Pentium4@3.4GH $\mathrm{GPU}$, and the codes are written in Matlab with a Matlab 6.1 compiler.

Within the expiring time $T=0.5$ year, we compare three situations in each table below: none incentive fee collected (None), fee collected two times (Twice), and fee collected four times (Quarterly). Between tables, option prices with respect to different volatility dynamics are compared. For the simplest case, let growth rate $G$ of the HWM and basic MF be zero. The parameters are $S_{0}=H_{0}=100, r=0.05, q=0.20$, and number of periods $=180$. Standard errors are in parentheses. In Table 1 , the value of constant volatility $=0.15$. For the GBMP in Table 2 and 3, we take $\sigma_{0}=0.15, \alpha=0.05, \theta=0.08$. For the SRMRP in Table 4 and 5, we use $v_{0}=0.0225, k=1.5, \bar{v}=0.0225$.

Table 1: Estimated HWM lookback option price with constant volatility.

\begin{tabular}{|l|l|l|l|l|}
\hline $\begin{array}{l}\text { Payment } \\
\text { frequency }\end{array}$ & 1,000 & 5,000 & 10,000 & 100,000 \\
\hline draws & & & & \\
(Plain MC) & 6.7703 & 6.9720 & 7.0124 & 7.0092 \\
None & $(0.1738)$ & $(0.0781)$ & $(0.0565)$ & $(0.0179)$ \\
Twice & 7.2202 & 7.3837 & 7.4535 & 7.4912 \\
& $(0.1819)$ & $(0.0813)$ & $(0.0589)$ & $(0.0187)$ \\
Quarterly & 7.0960 & 7.2813 & 7.3326 & 7.3575 \\
& $(0.1788)$ & $(0.0799)$ & $(0.0577)$ & $(0.0183)$ \\
\hline (AV) & & & & \\
None & 7.0638 & 7.0348 & 7.0402 & 7.0057 \\
Twice & $(0.0720)$ & $(0.0337)$ & $(0.0239)$ & $(0.0075)$ \\
& 7.5564 & 7.5247 & 7.5241 & 7.4904 \\
Quarterly & $(0.0724)$ & $(0.0341)$ & $(0.0241)$ & $(0.0076)$ \\
& 7.4038 & 7.3819 & 7.3864 & 7.3564 \\
& $(0.0728)$ & $(0.0340)$ & $(0.0241)$ & $(0.0076)$ \\
\hline
\end{tabular}

As shown from these results, the option prices of the SRMRP are lower than those of the GBMP or the constant volatility. In both GBMP and SRMRP, the option price is an increasing function of the correlation $\rho$. It is also worth noticing that the more frequently the incentive fee is paid, the lower the option price, and the price is the lowest when nothing paid. One possible explanation is the price of the underlying asset reduces a portion when the incentive fee is 
collected, and it is much difficult for the asset price to reach a new high. Finally, antithetic variate method can reduce the standard error by a factor of about 2 .

Table 2: $\quad$ Estimated HWM lookback option price with GBMP and $\rho=0$.

\begin{tabular}{|c|c|c|c|c|}
\hline $\begin{array}{l}\text { Number of } \\
\text { Payment } \\
\text { frequency }\end{array}$ & 1,000 & 5,000 & 10,000 & 100,000 \\
\hline (Plain MC) & 7.1819 & 7.0649 & 7.1354 & 7.1217 \\
\hline None & $(0.1823)$ & $(0.0802)$ & $(0.0570)$ & $(0.0181)$ \\
\hline Twice & $\begin{array}{l}7.6057 \\
(0.1897)\end{array}$ & $\begin{array}{l}7.4745 \\
(0.0831)\end{array}$ & $\begin{array}{l}7.5723 \\
(0.0593)\end{array}$ & $\begin{array}{l}7.5996 \\
(0.0189)\end{array}$ \\
\hline Quarterly & $\begin{array}{l}7.5116 \\
(0.1867)\end{array}$ & $\begin{array}{l}7.3761 \\
(0.0818)\end{array}$ & $\begin{array}{l}7.4604 \\
(0.0583)\end{array}$ & $\begin{array}{l}7.4697 \\
(0.0186)\end{array}$ \\
\hline$(\mathrm{AV})$ & & & & \\
\hline None & $\begin{array}{l}7.2014 \\
(0.0797)\end{array}$ & $\begin{array}{l}7.1426 \\
(0.0343)\end{array}$ & $\begin{array}{l}7.1445 \\
(0.0243)\end{array}$ & $\begin{array}{l}7.1207 \\
(0.0077)\end{array}$ \\
\hline Twice & $\begin{array}{l}7.6753 \\
(0.0797)\end{array}$ & $\begin{array}{l}7.6275 \\
(0.0346)\end{array}$ & $\begin{array}{l}7.6262 \\
(0.0245)\end{array}$ & $\begin{array}{l}7.6038 \\
(0.0077)\end{array}$ \\
\hline Quarterly & $\begin{array}{l}7.5468 \\
(0.0801)\end{array}$ & $\begin{array}{l}7.4935 \\
(0.0348)\end{array}$ & $\begin{array}{l}7.4922 \\
(0.0246)\end{array}$ & $\begin{array}{l}7.4701 \\
(0.0078)\end{array}$ \\
\hline
\end{tabular}

Table 3: $\quad$ Estimated HWM lookback option price with GBMP and $\rho=0.2$.

\begin{tabular}{|l|l|l|l|l|}
\hline \multicolumn{1}{|c|}{$\begin{array}{c}\text { Number of } \\
\text { Payment } \\
\text { frequency }\end{array}$} & 1,000 & 5,000 & 10,000 & 100,000 \\
\hline $\begin{array}{l}\text { (Plain MC) } \\
\text { None }\end{array}$ & & & & \\
& $\begin{array}{l}7.2125 \\
(0.1798)\end{array}$ & $\begin{array}{l}7.1116 \\
(0.0798)\end{array}$ & $\begin{array}{l}7.1802 \\
(0.0569)\end{array}$ & $\begin{array}{l}7.1528 \\
(0.0180)\end{array}$ \\
Twice & $\begin{array}{l}7.6529 \\
7.5318\end{array}$ & 7.6243 & 7.6352 \\
& $(0.1874)$ & $(0.0828)$ & $(0.0592)$ & $(0.0188)$ \\
Quarterly & 7.5621 & 7.4343 & 7.5123 & 7.5051 \\
& $(0.1839)$ & $(0.0581)$ & $(0.0581)$ & $(0.0185)$ \\
\hline AV) & & & & \\
None & 7.1746 & 7.1776 & 7.1843 & 7.1513 \\
& $(0.0811)$ & $(0.0354)$ & $(0.0252)$ & $(0.0079)$ \\
Twice & 7.6606 & 7.6680 & 7.6696 & 7.6380 \\
& $(0.0820)$ & $(0.0362)$ & $(0.0257)$ & $(0.0081)$ \\
Quarterly & 7.5372 & 7.5337 & 7.5356 & 7.5042 \\
& $(0.0816)$ & $(0.0360)$ & $(0.0256)$ & $(0.0080)$ \\
\hline
\end{tabular}


Table 4: $\quad$ Estimated HWM lookback option price with SRMRP and $\rho=0$.

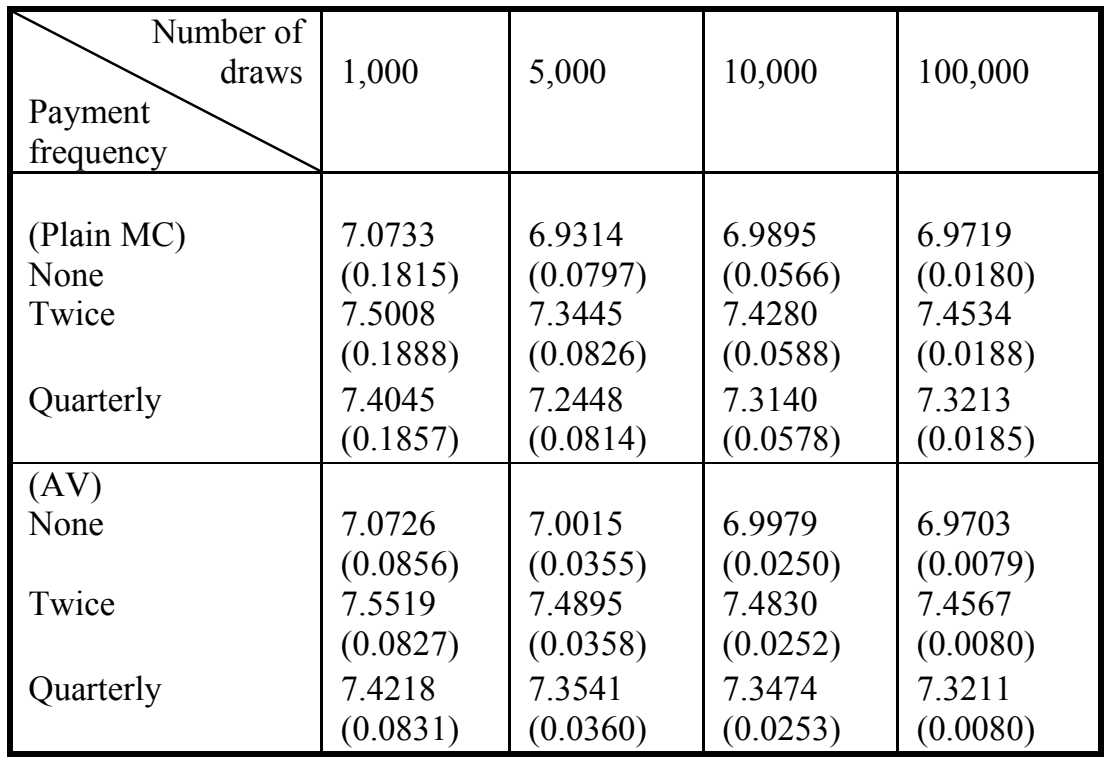

Table 5: $\quad$ Estimated HWM lookback option price with SRMRP and $\rho=0.2$.

\begin{tabular}{|c|c|c|c|c|}
\hline $\begin{array}{l}\text { Number of } \\
\text { Payment } \\
\text { frequency }\end{array}$ & 1,000 & 5,000 & 10,000 & 100,000 \\
\hline (Plain MC) & & & & \\
\hline None & $\begin{array}{l}7.1547 \\
(0.1773)\end{array}$ & $\begin{array}{l}7.0248 \\
(0.0785)\end{array}$ & $\begin{array}{l}7.0773 \\
(0.0559)\end{array}$ & $\begin{array}{l}7.0502 \\
(0.0177)\end{array}$ \\
\hline Twice & $\begin{array}{l}7.6073 \\
(0.1849)\end{array}$ & $\begin{array}{l}7.4543 \\
(0.0817)\end{array}$ & $\begin{array}{l}7.5312 \\
(0.0583)\end{array}$ & $\begin{array}{l}7.5421 \\
(0.0186)\end{array}$ \\
\hline Quarterly & $\begin{array}{l}7.5123 \\
(0.1814)\end{array}$ & $\begin{array}{l}7.3531 \\
(0.0803)\end{array}$ & $\begin{array}{l}7.4161 \\
(0.0573)\end{array}$ & $\begin{array}{l}7.4094 \\
(0.0182)\end{array}$ \\
\hline$(\mathrm{AV})$ & & & & \\
\hline None & $\begin{array}{l}7.1024 \\
(0.0802)\end{array}$ & $\begin{array}{l}7.0840 \\
(0.0349)\end{array}$ & $\begin{array}{l}7.0837 \\
(0.0247)\end{array}$ & $\begin{array}{l}7.0482 \\
(0.0077)\end{array}$ \\
\hline Twice & $\begin{array}{l}7.5981 \\
(0.0815)\end{array}$ & $\begin{array}{l}7.5836 \\
(0.0359)\end{array}$ & $\begin{array}{l}7.5784 \\
(0.0254)\end{array}$ & $\begin{array}{l}7.5441 \\
(0.0080)\end{array}$ \\
\hline Quarterly & $\begin{array}{l}7.4756 \\
(0.0811)\end{array}$ & $\begin{array}{l}7.4472 \\
(0.0357)\end{array}$ & $\begin{array}{l}7.4424 \\
(0.0253)\end{array}$ & $\begin{array}{l}7.4078 \\
(0.0079)\end{array}$ \\
\hline
\end{tabular}

\section{References}

[1] Basak, S., Pavlova, A. and Shapiro, A., Offsetting the incentives: risk shifting and benefits of benchmarking in money management. Working Paper 430303, MIT Sloan School of Management, 2003. 
[2] Black, F. and Scholes, M., The pricing of options and corporate liabilities. Journal of Political Economy, 81, pp. 637 654, 1973.

[3] Carpenter, J. N., Does option compensation increase managerial risk appetite? Journal of Finance, 55, pp. 2311 2331, 2000.

[4] Elton, E. J., Gruberand, M. J. and Blake, C. R., Incentive fees and mutual funds. Journal of Finance, 58, pp. 779 804, 2003.

[5] Feller, W., Two singular diffusion problems. Annals of Mathematics, 54, pp. $173182,1951$.

[6] Fung, W., and Hsieh, D., A primer on hedge funds. Journal of Empirical Finance, 6, pp. 309 331, 1999.

[7] Goetzmann, W. N., Ingersoll, J., and Ross, S.A., High water marks and hedge fund management contracts. Journal of Finance, 58, pp. 1685 1717, 2003.

[8] Heath, D. and Platen, E., A variance reduction technique based on integral representations. Quantitative Finance, 2, pp. 362 369, 2002.

[9] Heston, S. I., A closed form solution for options with stochastic volatility with applications to bond and currency options. Review of Financial Studies, 6, pp. 327 343, 1993.

[10] Hull, J. and White, A., The pricing of options on Assets with stochastic volatilities. Journal of Finance, 42, pp. 281 300, 1987.

[11] Jäckel, P., Monte Carlo methods in finance. Wiley Finance Series, New York: Wiley, 2002.

[12] Li, Z., Path dependent option: the case of high water mark provision for hedge funds. Ph.D. Thesis, University of Illinois at Chicago, 2002.

[13] Wiggins, J. B., Option values under stochastic volatilities. Journal of Financial Economics, 19, pp. 351 377, 1987.

[14] Wilmott, P., Howison, S. and Dewynne, J., The Mathematics of Financial Derivatives. Cambridge University Press, Cambridge, UK, 1995.

[15] Tang, J. H., Exotic option, stochastic volatility and incentive scheme. Ph.D. Thesis, University of Illinois at Chicago, 2005.

[16] Duffie, D., Dynamic asset pricing theory. Princeton University Press: Princeton and Oxford, pp 323 330, 2001. 